\title{
MODEL POVEZIVANJA TELEVIZIJSKIH STUDIJA I MOBILNA UKLJUČENJA KORIŠĆENJEM RTP/TCP PROTOKOLA
}

\author{
Mirko Milošević ${ }^{1}$, \\ Vladimir Maksimović2, *, \\ Mile Petrović2, \\ Branimir Jakšić2 \\ Petar Spalević ${ }^{3}$
}

'Visoka škola elektrotehnike i računarstva, Beograd, Srbija

${ }^{2}$ Fakultet tehničkih nauka, Univerzitet u Prištini, Kosovska Mitrovica, Srbija 3 Univerzitet Singidunum, Beograd, Srbija

Odgovorno lice:

Vladimir Maksimović

e-pošta:

vladimir.maksimovic@pr.ac.rs
Rezime:

U radu je prikazan jedan model za povezivanje više televizijskih studija i uključenja ekipe sa terena korišećnjem različitih protokola. Ovaj model je implementiran na Fakultetu tehničkih nauka u Kosovskoj Mitrovici. Strimovanje se vrši na serveru koji se nalazi u televiziji na kome je instalirana Wowza platforma i koja sadrži aplikacije za svaki studio sa kojim se vrši razmena i sa ekipom sa terena. Za strimovanje sa terena koristi se mobilni telefon gde se strimovanje obavlja pomoću 3G/4G mreže. Obzirom na to da je korisćenje mobilnih telefona veliko i da se koriste za razne vrste poslova, tako je i gledanje televizije na mobilnim telefonom postao neizbežni trend, sve više postoje aplikacije i softverska rešenja koje taj proces olakšavaju. Kako se prenos oslanja na internet vezu, strim je transkodovan u tri različite rezolucije i pri različitim bitskim protocima. U radu je prikazana ostvarena konekcija i analizirani paketi za sve tri rezolucije, odnosno grafički je prikazan broj paketa u jednoj sekundi za posmatrani određeni interval, kao i broj izgubljenih paketa.

Ključne reči:

striming, protokoli, digitalno emitovanje, mobilni prenos, televizija.

\section{UVOD}

Internet je u mnogome doprineo razvoju tehnologija, pa je danas komunikacija moguća sa velikim brzinama prenosa. Razvojem interenta doveo je do znatne evolucije u televizijskim sistemima, naročito u delu kada je u pitanju uživo prenos sa terena. Na ovaj nčin je televizijskim stanicama koje nemaju budžet kao one "velike" televizijske kuće, omogućen prenos sa terena. Razvojem pametnih mobilnih telefona i njihovom dominacijom na tržistu, prenos uživo sa terena postao je jos dostupniji i jeftinij. Ako se uzme u obzir i činjenica da danas pametni mobilni telefon ima svaki građanin onda je i svako sa pametnim mobilnim telefonom potencijalni “enkoder" sa terena. Obzirom na veliki razvoj mobilnih mreža i njihovog pouzdanog prenosa, u televizijskim sistemima koriste se GSM liknovi za direktna uključenja putem interneta koji rad baziraju na Bonding tehnologiji, odnosno Bonding serverima koji se zasnivaju na principu obeležavanja paketa i slanje paketa po najoptimalnijim putanjama, kao što je prikazano na Sl. 1 [1,2]. 
Međutim, jednostavniji i jeftiniji pricip ostvarivanja komunikacije sa terena i studija, korišćenjem $3 \mathrm{G} / 4 \mathrm{G}$ mreže ili Ethernet mreže, kao što je pomenuto, realizuje se pametnim mobilnim telefonm. Na Fakultetu tehničkih nauka u Prištini sa privremenim sedištem u Kosovskoj Mitrovici nalazi se televizijski studio koji opremljen tehnikom koja može da ispuni sve produkcijske i postprodukcijske zahteve. Pored kreiranja sadržaja programa, ostvarane je fizička veza sa lokalnim kablovskim distributerom, a distribucija programa preko IP veze. U redu je predstavljen striming sistem koji koristi različite protokole uz odgovarajući hardver i softver koji je već implementiran na ovom fakultetu. U pomenutoj televiziji nalazi se server na kome je instalirama Wowza platforma koja omgućuje vezu i razmenu sadržaja sa drugim televizijama ali i mogućnost za uživo uključenja mobilnim telefonom korišćenjem protokola za strimovanje.

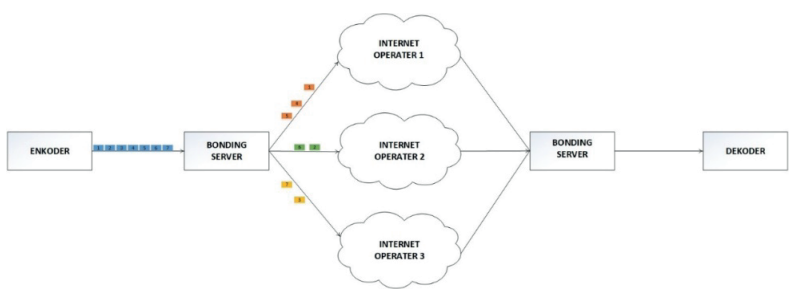

Sl. 1. Princip rada bonding servera

U Sekciji 1 dat je pregled korišćenih protokola za strimovanje, princip rada Wowza platforme, kao i šema implementirane veze sa ostalim televizijskim stanicama i uključivanje uživo sa terena korišćenjem mobilnih telefona. U Sekciji 2 prikazana je implementacija modela koji je realizovan u televiziji na Fakultetu tehničkih nauka. U Sekciji 3 prikazani su testovi i analize prilikom povezivanja drugih studija i prilikom uživo uključenja sa terena.

\section{STRIMING PROTOKOLI}

Striming (streaming) je termin koji označava emitovanje sadržaja preko Interneta krajnjem korisniku. Materijali koji su pripremljeni za striming se startuju automatski i ne zadržavaju se na računaru korisnika. Kvalitet emitovanog digitalnog programa najviše zavisi od kvaliteta Internet konekcije korisnika. Da bi se prenos realizovao koriste se različiti protokoli kao što su TCP (Transsmision Control Protocol) i UDP (User Datagram Protocol), što zavisi od načina željenog prenosa i opreme koja se koristi $[3,4]$.
TCP protokol koji je najčešće korišćen protokol na internetu. Na početku konekcije uspostavlja se konekcija (vrši se rukovanje) između predajnika i prijemnika i predajnik je u svakom trenutku upoznat sa stanjem prijemnika. TCP radi sa Internet Prtokolom (IP - Internet Protocol), koji definiše kako će se paketi poslati između ostvarene konekcije. TCP uspostavlja vezu i održava sve dok prijemna i predajna strana ne razmene poruke tj. pakete. Određuje kako podatke poslati u pakete, odnosno u koja mreža može primiti pakete, upravlja kontrolom protoka. Namenjen je za prenos podataka bez greške, odnosno radi retransmisiju propalih paketa kao i potvrdu da su isti stigli. Na primer, kada server šalje HTML (Hypertext Markup Language) podatak do klijenta, on koristi HTTP (The Hypertext Transfer Protocol) protkol. HTTP traži dozvolu od TCP sloja da bi uspostavio konekciju i poslao fajl. TCP nakon toga deli podataka na pakete, broji i nakon toga ih prosleđuje IP sloju. TCP sloj na strain kijenta čeka sve dok svi paketi ne stiku, nakon toga šalje potvrdu da su paketi stigli i traži retransmisiju samo onih paketa koji nisu stigli. Nakon toga, sklapa sve pakete u jedan fajl i dostavlja klijentu. Retransmisija i promena redosleda paketa može dovesti do latencija u TCP strimu. Aplikacije koje su vremenski osetljive, kao što su VoIP (Voice over Internet Protocol) i strimovanje video signala, uglavnom se oslanjaju na UDP pretokol, koji znatno smanjuje latenciju i dziter [5].

UDP je protokol za prenos signala i osnovna karakteristika je "konekcija bez povezivanja" - predajnik nema informaciju o stanju na prijemu. Bez obzira da li je predajnik u stanju da primi i dekoduje pakete ili je došlo do zagušenja i prijemnik ne može da dekoduje signal - enkoder šalje pakete jer nema povratnu informaciju. Kada se pošalju podaci, nema načina da se sazna da li su stigli ili da li su stigli redosledom kojim su poslati. Međutim, podaci koji stižu, stižu brzo sto je bitno za neke vrste servisa tj. aplikacija kojima je brzina važnija od pouzdanosti isporuke podataka (npr. realtime audio i video). Zbog toga se veoma često koriste u takvim mrežama gde je bitno da veza postoji iako će biti gubitaka paketa. Međutim, u nekim slučajevima može se koristiti napredna tehnika korekcija greške kako bi se poboljšao kvalitet audia i videa. U drugim aplikacijama, mogu se implementirati testovi pouzdanosti u aplikacionom sloju. Na primer, ako klijent pošalje kratak UDP zahtev serveru, može pretpostaviti da je paket izgubljen ako ne dobije odgovor u dogovorenom periodu. To je jedan način na koji funkcioniše DNS (Domain Name Server). DNS takođe može raditi i preko TCP [6]. 
Postoji nekoliko slučajeva kada je bolje koristiti UDP umesto TCP protokola, kada je blok podataka koji treba poslati mali, veličine jednog paketa - jednostavnije je, brže i efikasnije prenositi samo podatke (uz zaglavlje UDP-a), pa u slučaju pogrešno primljene poruke ponoviti slanje, nego uspostavljati vezu i proveravati pouzdanost prenosa [7].

Prilikom stimovanja, u zavisnosti od aplikacije koja se želi primeniti, odnosno od projektovanog sistema i željenog načina prenosa koriste se i takozvani "protokoli za strimovanje” koji se baziraju na TCP i UDP protokolima, kao što su RTP (Real Time Protocol), RTSP (Real Time Streaming Protocol), RTMP (Real Time Messaging Protocol) i HLS (HTTP Live Streaming) [8].

RTP i RTSP su dva sasvim različita protokola koja se obično koriste zajedno. Iako se često pominje samo jedan obično se misli na oba protokola tj. RTP/RTSP (RTP može raditi bez RTSP). RTSP koristi za kontrolu i uspostavljanje sesije između predajne i prijemne strane. RTSP radi preko TCP a RTP se šalje preko UDP (video i audio se šalju preko par UDP portova). Ovo predstavlja dobru pogodnost ali je problematično kada se šalje preko javnih mreža, u tom slučaju se zahteva više portoava. RTP ima zadatak da šalje podatke u realnom vremenu, kao što je u ovom radu uživo uključenja i povezivanje više studija, odnosno transportni protokol iskorišćen za strimovanje putem internet protokola. RTP portokol može efikasno rešiti problem kašnjenja u mreži na štetu kvaliteta i može rešiti sinhronizaciju podataka različitih strimova. Enkodovanje podatak (audio i video) enkapsulirano je u RTP pakete, zaglavlje paketa pruža informaciju o rednom broju paketa pri čemu prijemnik može reorganizovati podatke paketa ali RTP ne može pružati pouzdan mehanizam za prenos paketa u sekvencu, niti pruža kontrolu protoka. Kontrola protoka se oslanja i zavisi od RTCP (Real Time Control Protocol) protokola $[8,9]$.

Razvojem i rastopm popularnosti Flash tehnike na internetu, za strimovanje se veoma često koristi RTMP (Real Time Message Protocol) porotkol. RTMP koristi TCP protokol na transportnom nivou što efikasno rešava problem gubitka paketa. RTMP je baziran na TCP protkolu za strimovanje audia, videa i podataka putem internet korišćenjem [10-12].

Još jedan od često korišćenih protokola za strimovanje jeste HLS (HTTP Live Streaming) protkol, koji je razvijen od strane Apple kompanije i baziran je na HTTP protokolu. Usmeren je uglavnom ka mobilnim uređajima zasnovanim na iOS operativnom sistemu kao što su iPhone, iPad, AppleTV ili personalnim računarima sa Apple-ovim operativnim sistemima. Karakteristika je kašnjenje od nekoliko sekundi ali veoma stabilana veza. Princip rada je da se preuzme jedan deo multimedijalnog sadržaja i uvek preuzme sledeći deo sadžaja pre nego što počne reprodukciju trenutnog dela. HLS se koristi za sisteme gde kašnjenje nije značajan faktor, ali polako ovaj standard počinje da se implementira u svim vodećim CDN (Content Delivery Network) serverima $[13,14]$.

Mnogi današnji sistemi za strimovanje, počevši od onih kompleksnijih i skupljih do onih jednostavnijih i jeftinijih koriste se ovi protokoli za strimovanje. Takođe, koriste ih i popularni sistemi kao što su YouTube, Ustream, Twitch, Wowza itd. U imlementiranom sistemu na Fakultetu tehničkih nauka, na serveru je instaliran Wowza Streaming Engine [15].

Wowza Streaming Engine (poznat i kao Wowza Media Server) je striming server softver razvijen od strane Wowza Media Sistems. Server se koristi za uživo strimovanje (Live straming) i strimovanje na zahtev (VOD - Video on Demand) [16].

Za strimovanje je moguće koristiti kako hardverske enkodere, tako i softverske aplikacije instalirane na desktop, laptop, tablet računarima, smart telefonima a moguće je strimovanje i sa enkodera koji su fabrički ugrađeni u ENG (Electronic News Gathering) kamerama. Pomoću servera na kome se nalazi Wowza Engine, može se $\mathrm{u}$ isto vreme primati strimovi a $\mathrm{u}$ isto vreme $\mathrm{i}$ slati. Moguće je vezu bazirati i na TCP protokolu ali i na UDP. Za strimovanje koristi i podržava veliki broj striming protokola kao što su gore pomenuti a koji će biti korišćeni u ovom radu. Princip rada servera sa Wowza Streaming Engine prikazan je na Sl. 2 [16].

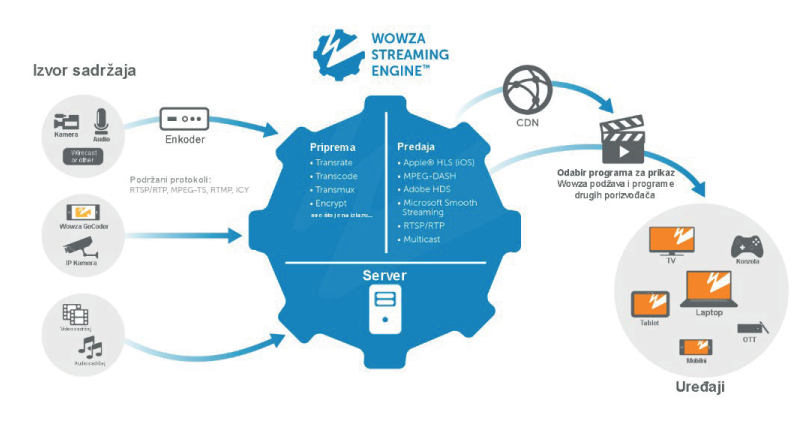

Sl. 2. Princip rada Wowza striming server-a

Wowza Streaming Engine se kao softverska aplikacija instalira na Server računar koji je preko mrežne kartice povezan na internet pri čemu je nephodno obezbediti 
statičnu IP adresu sa odgovarajućim protokom (protok interneta download i upload zavisi od potreba korisnika, tj. koliko dolaznih strimova će biti u isto vreme slato ka Wowzi i koliko uređaja na prijemu reprodukuje u istom trenutku te strimove sa Wowze) [16].

\section{IMPLEMENTACIJA MODELA}

Struktura televizijskog sistema je projektovana tako da bude multifunkcionalna i zadovolji sve televizijske standardne i kriterijume. Kompletan televizijski sistem je adaptiran u prostorijama Fakulteta tehničkih nauka i projektovan je tako da služi za edukativne svrhe, ali i da ispuni sve produkcijske i tehničke zahteve. Pored distribucije signala ka kablovkoj (DVB-C) i zemaljskoj mreži (DVB-T2), moguće je distribuirati signal korišćenjem internet protokola, formirajući tako televizijski sistem baziran na internet protoklu (IPTV). Iako se IP protokol koristi za prenos video signala preko svih vrsta mreža, realizovani studio pruža mogućnost ostvarivanja konekcije sa drugim televizijskim sistemima u vidu razmene signala. Ta razmena se postiže tako što se u studiju nalazi server na kome je instaliran Wowza Streaming Engine platforma, dok se na prijemoj strani nalazi STB (Set Top Box) uređaj koji dekodira dolazne pakete stimovanog signala.

Na Sl. 3 prikazan je način realizacije konekcije TV sistema sa drugim TV sistemima i uređajima.

Najpre se na serveru, koji se nalazi u mašinskoj sobi, instalira Wowza Stremaing Engine na kojem se konfigurišu aplikacije koje će omogućiti razmenu signala sa drugim televizijskim studiom i mobilnim telefonom koji se nalazi na terenu. Za svaki strim se pravi nova aplikacija, na primer, pravi se aplikacija za strim od studija iz Kosovske Mitrovice ka strudiju Visoke škole elektrotehnike i računarstva u Beogradu, aplikacija za uključivanje mobilnim telefonom sa terena koju će moći da koriste oba studija i treća aplikacija iz studija u Beogradu ka studiju u Kosovskoj Mitrovici. Na tom istom serveru otvaraju se dva porta 8088 i 1935 kako bi se server mogao daljinski konfigurisati i omogućiti da se sa njega strimuje. Pomoću programa Wirecast [17], koji je instaliran na računaru u studiju i koji služi kao enkoder, konfigurišu se paramitri servera, odnosno javna IP adresa, port i naziv prethodno kreirane aplikacije u Wowzi. Na taj način formiran je strim koji drugi studio može prihvatiti pomoću STB uređaja ili testirati u VLC programu. $\mathrm{Na}$ Sl. 4 prikazan je strim koji se šalje iz studija iz Kosovske Mitrovice, a na Sl. 5 prikazan je stim koji se šalje iz studija iz Beograda.

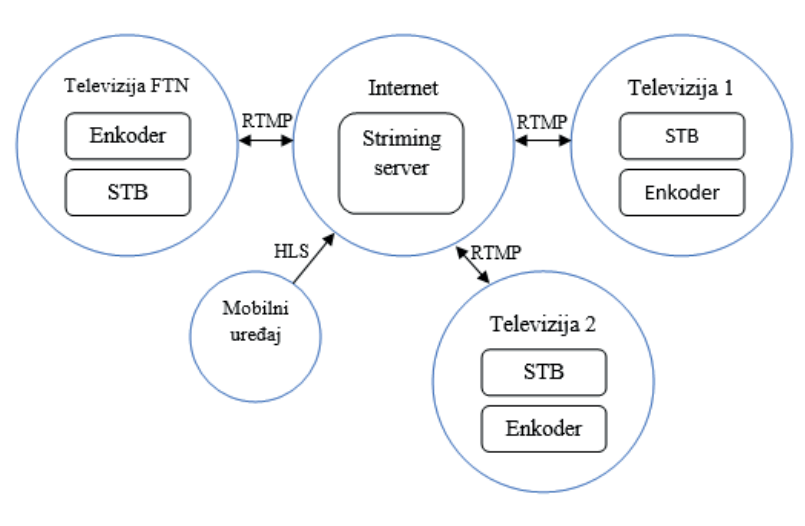

Sl. 3. Pricip realizacije konekcija TV sistema

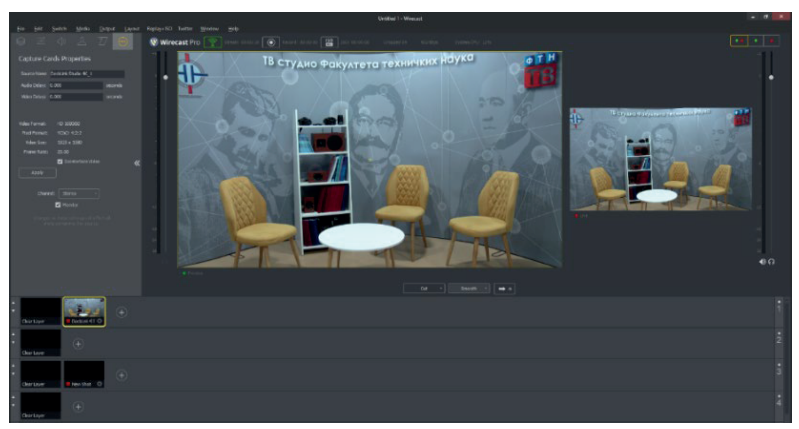

Sl. 4. Strimovanje signala iz studija u Kosovskoj Mitrovici

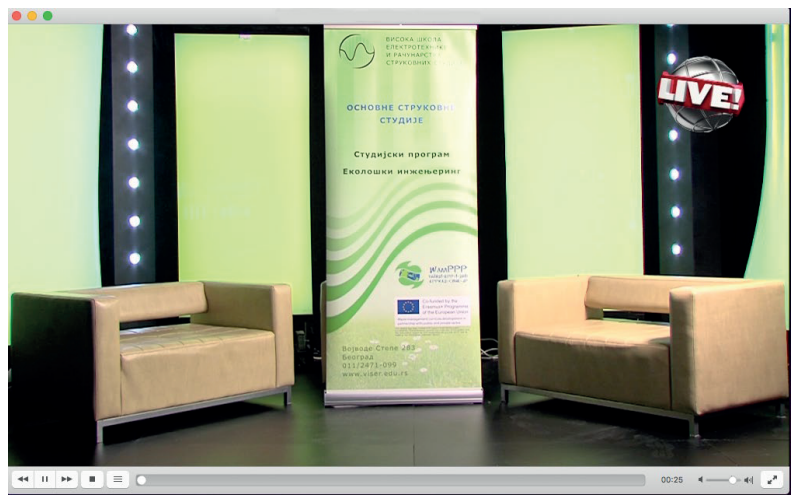

Sl. 5. Strimovanje signala iz studija u Beogradu

Slanje strima sa terena korišćenjem mobilnog telefona realizovano je pomoću GoCoder aplikacije [18], odnosno aplikacije koju je realizovala Wowza kompanija. U aplikaciji se unosi ista adresa servera i port, sa jedinom razlikom naziva aplikacije. Na Sl. 6 prikazano je slanje strima sa terena pomoću mobilnog telefona korišćenjem $4 \mathrm{G}$ mreže. 


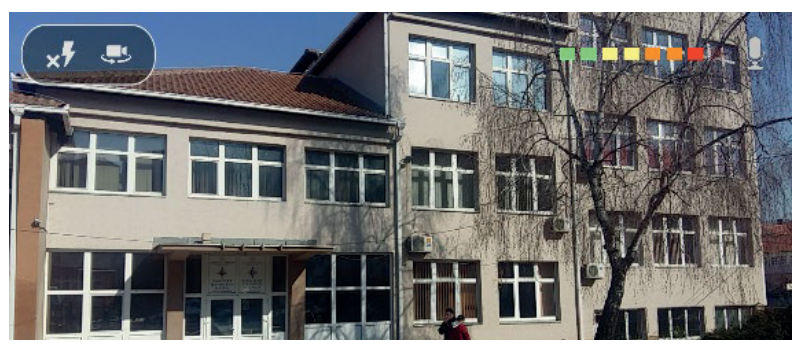

Sl. 6. Strimovanje signala mobilnim telefonom

$\mathrm{Na}$ ovaj način realizovan je prenos sa terena mobilnim telefonom i uspostava veze sa drugim studiom korišćenjem RTMP i HLS protokola. Prijem signala koji se šalje mobilnim telefonom u samom studiju konfirise se na STB uređaju tako što se unosu parametri strima (javna IP adresa, port i naziv aplikacije, u ovom slučaju to izgleda ovako: rtmp://147.91.144.107:1935/ftn/mLive ili ako se strimuje mobilnim telefonom sa iOS operativnim sistemom to izgleda ovako: http://147.91.144.107:1935/ $\mathrm{ftn} / \mathrm{mLive} /$ playlist.m3u8).

\section{TESTIRANJE I ANALIZA}

Na Sl. 7 dat je pregled aktivnih konekcija i iskorišćenih protokola. Sa Sl. 7 se može videti da je ukupan broj ostvarenih konekcija četiri, gde konekcije koje koriste RTMP protokol predstavljaju vezu između studija, dok HLS predstvalja vezu sa ekipom na terenu. U zavisnosti od situacije, za ostvarivanje veze, mogu se koristiti i ostali protokoli.

\begin{tabular}{|c|c|}
\hline Total: & 4 \\
\hline Adobe HDS: & 0 \\
\hline Adobe RTMP: & 3 \\
\hline Apple HLS: & 1 \\
\hline Microsoft Smooth: & 0 \\
\hline MPEG DASH: & 0 \\
\hline RTSP/RTP: & 0 \\
\hline
\end{tabular}

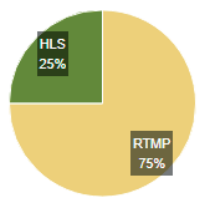

Sl. 7. Monitoring aktivnih konekcija i protokola

Obzirom na to da je uspostavljanje veze sa ekipom na terenu i razmena signala sa drugim televizijskim studijima preko internet veze, stabilnost i kvalitet, kako objektivni tako i subjketivni zavise upravo od brzine internet konekcije. Međtuim, da bi se video strim prilagodio svim korisnicima, na serveru na kome je instaliran Wowza Sreaming Engine prilikom strimovanja izvršeno je transkodovovanje strima gde se koriste različite rezolucije i različiti bitski protoci koji znatno više utiču na kvalitet. Analizirane su tri kategorije rezolucije video strima. U Tabeli 1 dati su parametri enkodera za primenjenu SD (Standard Definition) rezoluciju, HD (High Definition) rezoluciju i FullHD (Full High Definition) rezoluciju.

Tabela 1. Parametri enkodera prilikom strimovanja

\begin{tabular}{lccc}
\hline & SD & HD & FullHD \\
\hline \multicolumn{1}{c}{ Rezolucija } & $720 \times 576$ & $1280 \times 720$ & $1920 \times 1080$ \\
\hline $\begin{array}{l}\text { Broj frejmova } \\
\text { u sekundi }\end{array}$ & 25 & 25 & 25 \\
\hline $\begin{array}{l}\text { Prosečni } \\
\text { video bitski } \\
\text { protok [kb/s] }\end{array}$ & 1025 & 2252 & 4500 \\
\hline $\begin{array}{l}\text { Audio bitski } \\
\text { protok [kb/s] }\end{array}$ & 128 & 128 & 128 \\
\hline $\begin{array}{l}\text { Frekvencija } \\
\text { odmeravanja } \\
\text { audio signala } \\
{[\text { Hz] }}\end{array}$ & 44100 & 44100 & 44100 \\
\hline
\end{tabular}

Na Sl. 8, Sl. 9 i Sl. 10 dat je prikaz broja primljenih paketa u jednoj sekundi u posmatranom interval strimovanja od 60 sekundi, kao i broj izgubljenih paketa prilikom strimovanja SD, HD i FullHD rezolucije, respektivno. Grafici su dobijeni korišćenjem softverskog paketa Wireshark [19] koji se koristi za analizu IP paketa. Gornji grafik se odnosi na broj primljenih paketa od strane servera ka korisniku, dok donji grafik predstavlja broj izgubljenih paketa.

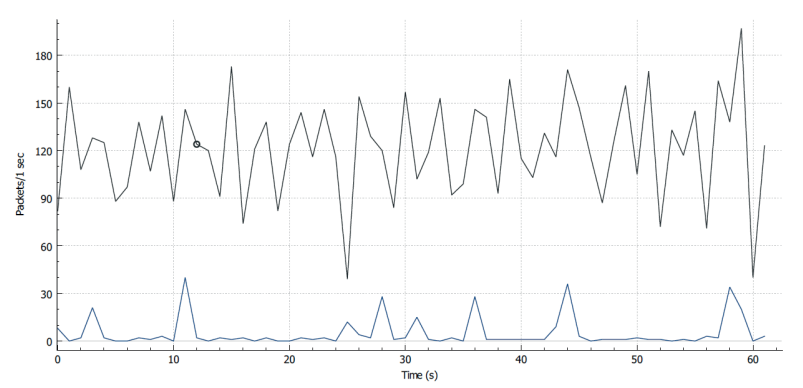

Sl. 8. Broj prenetih i izgubljenih paketa i za posmtarani interval od 60s za SD rezoluciju 


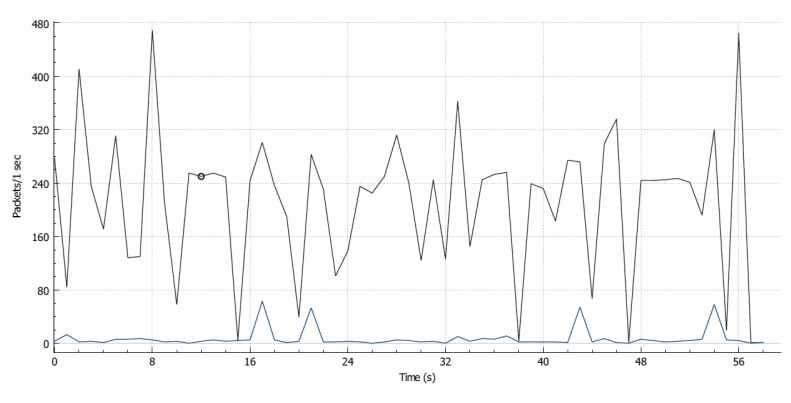

Sl. 9. Broj prenetih i izgubljenih paketa i za posmtarani interval od 60s za HD rezoluciju

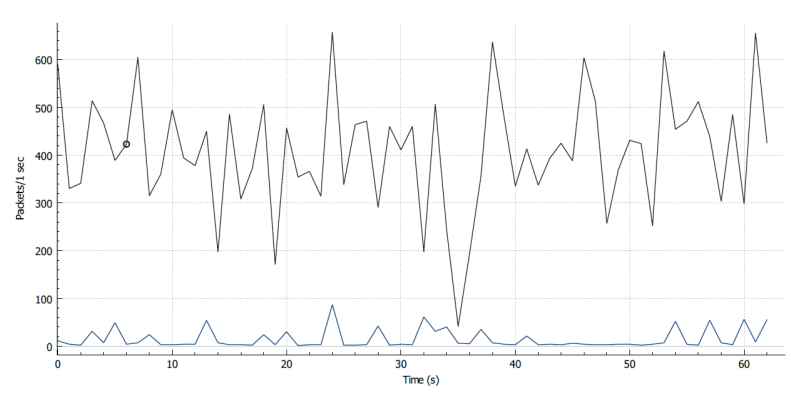

Sl. 10. Broj prenetih i izgubljenih paketa i za posmtarani interval od 60s za FullHD rezoluciju

Sa datih slika se može videte da broj primljenih paketa raste sa porastom rezolucije, odnosno porastom bitskog protoka, jer je potreban prenos veće količine informacija. Takođe, povećava se i broj izgubljenih paketa ali ukoliko prijemnik (korisnik) raspolaže zahtevanim bitskim protokom (koji je veći ili jednak bitskom protoku strima koji se šalje), ovaj broj gubljenja paketa neće narušavati kvalitet prijema signala.

\section{ZAKLJUČAK}

U radu je prikazan jedan model za povezivanje više televizijskih studija korišćenjem internet veze. Prikazani model omogućava i ustpostavu veze sa mobilnih lokacija korišćenjem pametnih telefona. Model je implementiran na Fakultetu tehničkih nauka u Kosovskoj Mitrovici, a veza je testrana sa televizijskim studiom koji se nalazi na Visokoj školi elektrotehnike i računarstva u Beogradu, kao i sa mobilnim uređajem koji se nalazi na udaljenim lokacijama. Tom prilikom izvršena je analiza paketa za tri različite rezolucije (različitih bitskih protoka).

Predstavljeni model može se implementirati bez upotrebe mikrotalasnih veza ili drugih radio frekventnih veza (zemaljskih i satelitskih) čime se troškovi realizacije svode na minimum. Prednost ovog modela se ističe prilikom uključenja sa udaljenih lokacija, gde je samo potreban mobilni telefon sa internet vezom i odgovarajućom aplikacijom. Takođe, ističe se malim kašnjenjem signala čak i pri višim rezolucijama videa koje iznosi oko 3 sekunde i to ga čini pogodnom za implementaciju i u profesinalnim televizijskim kućama).

\section{ZAHVALNOST}

Ovaj rad je rađen u okviru istraživačkih projekta Ministarstva nauke i tehnološkog razvoja Republike Srbije: TR32023, TR35026 i III47016.

\section{LITERATURA}

[1] S. H. R. Bukhari, M. H. Rehmani, and S. Siraj, "A Survey of Channel Bonding for Wireless Networks and Guidelines of Channel Bonding for Futuristic Cognitive Radio Sensor Networks," IEEE Communications Surveys \& Tutorials, vol. 18, no. 2, 2016, pp. 924-948.

[2] L. Montalvo, G. Mace, C. Chapel, S. Defrance, T. Tapie, and J. Le Roux, "Implementation of a TV studio based on Ethernet and the IP protocol stack," IEEE International Symposium on Broadband Multimedia Systems and Broadcasting, Bilbao, Spain, 2009, pp. 1-7.

[3] P. Zhao, J. Li, J. Xi, and X. Gou, Xuerong. (2012). "A Mobile Real-Time Video System Using RTMP," Fourth International Conference on Computational Intelligence and Communication Networks, Ghaziabad, India, 2012, pp. 61-64. DOI: 10.1109/ CICN.2012.18.

[4] D. Chu, C. Jiang, Z. Hao, and W. Jiang, "The Design and Implementation of Video Surveillance System Based on H.264, SIP, RTP/RTCP and RTSP," Sixth International Symposium on Computational Intelligence and Design, Hangzhou, China, 2013, pp. 3943.

[5] Z. Yue, X. Zhang, Y. Ren, J. Li, and Q. Zhong, "The performance evaluation and comparison of TCPbased high-speed transport protocols," IEEE International Conference on Computer Science and Automation Engineering, Beijing, China, 2012, pp. 509-512.

[6] Z. Yue, Y. Ren, and J. Li, "Performance evaluation of UDP-based high-speed transport protocols," IEEE 2nd International Conference on Software Engineering and Service Science, Beijing, 2011, pp. 69-73. 
[7] F. Al-Dhief, N. Sabri, N. M. Abdul Latiff, N. N. Nik Abd Malik, M. Albadr, M. Mohammed, R.N. AlHaddad, Y. Dawood, M. K. Abd Ghani, and O. I. Obaid, "Performance comparison between TCP and udp protocols in different simulation scenarios," International Journal of Engineering and Technology (UAE), vol. 7, 2018, pp. 172-176.

[8] A. Aloman, A. I. Ispas, P. Ciotirnae, R. SanchezIborra, and M. D. Cano, "Performance Evaluation of Video Streaming Using MPEG DASH, RTSP, and RTMP in Mobile Networks," 8th IFIP Wireless and Mobile Networking Conference (WMNC), Munich, Germany, 2015, pp. 144-151.

[9] P. Liang, and C. S. Yang, "Research and implementation of voice transmission based on RTP protocol," International Conference on Computational Problem-Solving, 2010, Lijiang, China, pp. 416-419.

[10] A. Nurrohman, and M. Abdurohman, "High Performance Streaming Based on H264 and Real Time Messaging Protocol (RTMP)," 6th International Conference on Information and Communication Technology (ICoICT), Bandung, Indonesia, 2018, pp. 174-177.

[11] D. Doder, N. Četić, M. Popović and J. Kovačević, "Realisation of server application for acoustic sensors based on RTSP, RTP protocols," 23rd Telecommunications Forum Telfor (TELFOR), Belgrade, Serbia, 2015, pp. 516-519.

[12] X. Lei, X. Jiang, and C. Wang, "Design and Implementation of a Real-Time Video Stream Analysis System Based on FFMPEG," Fourth World Congress on Software Engineering (WSCE), Kuala Lumpur, Malaysia, 2013, pp. 212-216, DOI: 10.1109/WCSE.2013.38.
[13] V. Kosjer, N. Popović, N. Fimić and N. Šoškić, "Android multimedia environment extension with support for adaptive transport protocol," 13th International Conference on Advanced Technologies, Systems and Services in Telecommunications (TELSIKS), Nis, Serbia, 2017, pp. 73-76.

[14] R. Vulin, T. Samardžić, Đ. Simić and B. Kovačević, "One software solution for processing WebVTT subtitles during playback of hls streams using FFmpeg libraries," 23rd Telecommunications Forum Telfor (TELFOR), Belgrade, Serbia, 2015, pp. 760-763.

[15] T. Mantoro, M. A. Ayu and D. Jatikusumo, "Live video streaming for mobile devices: An application on android platform," 2nd International Conference on Uncertainty Reasoning and Knowledge Engineering, Jalarta, Jakarta, 2012, pp. 119-122.

[16] Softverski paket Wowza Streaming Engine: https:// www.wowza.com/products/streaming-engine

[17] Softverski paket Wirecasat: https://www.telestream. net/wirecast/

[18] Android i iOS aplikacija GoCoder: https:// itunes.apple.com/us/app/wowza-gocoder/ id640338185? $\mathrm{mt}=8$

[19] [Softverski paket Wireshark: https://www.wireshark.org/ 